\title{
Application of Sieve-Tray Air Strippers to the Treatment of Surfactant-Containing Wastewaters
}

\author{
Tohren C. G. Kibbey \\ School of Civil Engineering and Environmental Science, U niversity of O klahoma, N orman, OK 73019 \\ Kurt D. Pennell \\ School of Civil and Environmental Engineering, Georgia Institute of Technology, A tlanta, GA 30332 \\ Kim F. Hayes \\ Dept. of Civil and Environmental Engineering, The U niversity of M ichigan, A nn A rbor, M I 40809
}

\begin{abstract}
Using sieve-tray air stripping as a means of removing contaminants from surfactant solutions was studied to determine if tray air stripping can be applied successfully to treating surfactant-containing wastewaters and, if so, to develop a quantitativeapproach for designing tray air-stripping systems for treating surfactant-containing wastewaters. High-concentration surfactant solutions were prepared and contaminated with five different $v$ olatile organic compounds. Removal of the organic compounds was evaluated using a commercial sieve-tray air stripper. Overall, the air stripper was able to efficiently remove the contaminants from solution, and correction of H enry's $L$ aw constants for micellar solubilization-induced volatility reduction allowed tray air-stripper design equations to quantitatively predict air-stripper removal for all contaminants. Foaming within the air stripper could be controlled with low concentrations of a silicone-polymer antifoaming agent. Although adding antifoaming agents may be undesirable for some applications, other applications can benefit from the operational and performance advantages of sieve-tray air strippers. I ssues related to air-stripper design for low- $v$ olatility compounds are also discussed.
\end{abstract}

\section{Introduction}

Surfactants have shown significant potential for use in in situ and ex situ environmental remediation applications, and are also widely used in industrial processes. An important consideration in the design of any surfactant-based process is the treatment and handling of contaminated surfactant solutions resulting from the process. B ecause of the relatively high cost of surfactants, cost-effective applications may require recycling and reuse of surfactants. In addition, removal of organic contaminants typically will be necessary prior to the discharge of waste-surfactant solutions.

For many classes of organic compounds, air stripping and related technologies (such as vacuum stripping) have been found to be very effective for treating contaminated surfactant solutions. M any studies reported to date have made use of packed-tower strippers (Clarke et al., 1993; O ma et al.,

Correspondence concerning this article should be addressed to C. G. Kibby.
1993; Lipe et al., 1996; Chiang et al., 1998; Choori et al., 1998). In practice, however, low-profile sieve-tray air strippers are widely used for air-stripping applications, due to their small size and ease of maintenance. U se of low-profile air strippers for surfactant solutions poses a unique set of problems that have not been addressed to date. In particular, the potential for foaming of surfactant solutions in tray air strippers is greater than in other air strippers due to the mechanism by which the air/water interfacial area is created. In addition, because surfactant solutions can dramatically reduce the volatility of organic compounds, a quantitative design approach is needed to predict the performance of tray air strippers when used with surfactant solutions.

The objective of the work presented here was to evaluate the use of sieve-tray air stripping as a means of removing contaminants from surfactant solutions. Specific goals were to determine if tray air stripping can be successfully applied 
to treatment of surfactant-containing wastewaters, and, if so, to develop a quantitative approach for designing tray airstripping systems for treating surfactant-containing wastewaters.

\section{Background}

A ir stripping is well-suited to removal of volatile compounds from contaminated aqueous solutions. Air-stripping systems work by contacting contaminated water with clean air, creating a large air/water interfacial area for transfer of contaminants from the water to the air. Volatile contaminants [that is, compounds with high Henry's Law constants $\left(\mathrm{K}_{\mathrm{H}}^{0}\right)$ ] are readily removed from water by air stripping. Devices for removal of volatile contaminants by air stripping can be characterized as supported-area devices or unsupportedarea devices (Berg, 1988). In supported-area devices, such as packed-tower air strippers, air/water interfacial area is physically supported by the geometry of the air stripper. In a packed tower, the flow of water over the packing material creates a thin liquid film (supported by the packing material) with a high surface area for mass transfer between the air and water phases. Correlations are available for prediction of mass transfer in packed-column air strippers, and have been found to provide very reasonable agreement with experimental data for nonsurfactant-containing wastewaters (K avanaugh and Trussell, 1980; Staudinger et al., 1990; Dvorak et al., 1996).

In unsupported-area devices, air/water interfacial area is produced by direct interaction between the air and water. Although several approaches can be used, one of the most common is a sieve-tray design. In a sieve-tray air stripper, water enters at the top of the device and flows across several perforated trays in series. Air enters the bottom of the system and is forced through the perforations in the trays and the liquid above. A ir pressure prevents water from leaking through the perforations. Surface area for mass transfer is created by the air bubbles passing through the liquid, as well as the droplets of water created as the air rapidly exits the liquid. B etween trays, water flows through downcomers, which prevent air from bypassing the perforated trays. Unlike packed towers, mass transfer in sieve-tray air strippers is quite difficult to predict a priori, although mechanistic models have been developed for specific systems (Prado and Fair, 1990; Chen and Chuang, 1993; B ennett et al., 1995). D esign of sieve tray air strippers typically requires determination of an efficiency factor, as will be discussed below.

\section{Sieve-tray air-stripper design equations}

To design a sieve-tray air stripper for treatment of dilute aqueous solutions, equations based on the equilibrium and operating line approach can be used. An analytical solution can be derived to describe the performance of an air stripper with $\mathrm{N}_{\mathrm{TH}}$ ideal (theoretical) trays (Perry and Green, 1997)

$$
\frac{x_{\text {in }}-x_{\text {out }}}{x_{\text {in }}-\left(y_{\text {in }} / K_{H}\right)}=\frac{S-S^{\left(N_{T H}+1\right)}}{1-S^{\left(N_{T H}+1\right)}}
$$

where

$x_{\text {out }}=$ aqueous concentration leaving the air stripper;

$\mathrm{x}_{\mathrm{in}}=$ aqueous concentration entering the air stripper; $\mathrm{y}_{\text {in }}=$ gas concentration entering the air stripper;

$\mathrm{N}_{\mathrm{TH}}=$ number of theoretical trays in the air stripper; and $\mathrm{S}=$ stripping factor, given by

$$
\mathrm{S}=\frac{\mathrm{G} \cdot \mathrm{K}_{\mathrm{H}}}{\mathrm{L}}
$$

where

$\mathrm{G}=$ gas flow rate;

$\mathrm{L}=$ liquid flow rate; and

$K_{H}=H$ enry's L aw constant, given by $K_{H}=y / x$.

B ecause trays in a real air stripper will not behave ideally, the actual number of trays needed to achieve the desired performance, $N_{A C}$, will be greater than the number of theoretical trays. To account for the difference, an overall tray efficiency is defined

$$
\epsilon=\frac{\mathrm{N}_{\mathrm{TH}}}{\mathrm{N}_{\mathrm{AC}}} .
$$

Tray efficiency can be influenced by properties of the compounds being stripped, properties of the fluids, flow paths within the air stripper, and extent of mixing within each tray (Perry and Green, 1997). A hypothesis of the work presented here was that the properties of the individual organic compounds being stripped would have a minor influence on the tray efficiency, relative to the influence of other systemspecific factors. A s such, an objective of this work was to determine if a single value of efficiency could be used to provide an adequate prediction of air-stripper performance of a particular air-stripper for a wide range of compounds.

\section{Air-stripping surfactant solutions}

Because surfactants are not volatile, air stripping can be used to remove contaminants from surfactant solutions with little or no impact on the surfactant concentration. However, because of the effects surfactants have on liquid properties, the performance of both supported-area and unsupportedarea devices can be substantially influenced by the presence of surfactants. Two specific surfactant effects most likely to influence air-stripping performance are (1) the reduction in volatility (H enry's law constant) due to solubilization, and (2) foam formation. These effects are discussed below.

Solubilization and Henry's Law Constant Reduction. Surfactant solutions have the potential to dramatically reduce $H$ enry's Law constants of organic compounds, due to solubilization of organic compounds by surfactant micelles. $\mathrm{M}$ icelles are aggregates of surfactant molecules that form at surfactant concentrations above the critical micelle concentration (CM C). CM C values vary from surfactant to surfactant, and are usually several orders of magnitude lower than surfactant concentrations used in typical applications; as such, most surfactant solutions considered for air-stripper design will be composed primarily of surfactant in micellar form. Surfactant micelles provide a hydrophobic sink for organic compounds. The partitioning of organic compounds into surfactant micelles from the surrounding water is known as solubilization. The Solubilization capacity of surfactant micelles can vary with surfactant and organic compound properties, and can be described by the weight solubilization ratio (W SR ), a measurable quantity. A model describing the effect of solu- 
bilization on volatility has been described by A nderson (1992). The model assumes that organic compounds associated with surfactant micelles are nonvolatile, while organic compounds not associated with surfactant micelles obey Henry's Law. Based on this assumption, an equation can be derived to correct the Henry's Law constant for solubilization

$$
K_{H}=\frac{K_{H}^{0}}{\left(1+W S R \cdot \frac{C_{\text {surf }}-C M C}{S_{\text {org }}}\right)}
$$

where

$$
\begin{aligned}
\mathrm{K}_{\mathrm{H}}= & \mathrm{H} \text { enry's } \mathrm{L} \text { aw constant corrected for solubilization; } \\
\mathrm{K}_{\mathrm{H}}^{0}= & \mathrm{H} \text { enry's } \mathrm{L} \text { aw constant in the absence of } \\
& \text { surfactant; } \\
\mathrm{C}_{\text {surf }}= & \text { aqueous surfactant concentration in mass units; } \\
\mathrm{CMC}= & \text { critical micelle concentration of the surfactant in mass } \\
& \text { units; } \\
\mathrm{S}_{\text {org }}= & \text { aqueous solubility of the organic compound in mass } \\
& \text { units; and } \\
W S R= & \text { weight solubilization ratio for the surfactant, given by } \\
& \left(\mathrm{C}_{\text {org }}-\mathrm{S}_{\text {org }}\right) /\left(\mathrm{C}_{\text {surf }}-\mathrm{CMC}\right),
\end{aligned}
$$

where $\mathrm{C}_{\text {org }}$ is the total organic compound concentration in mass units.

Equation 3 is applicable to surfactant concentrations above the CM C, and allows Henry's Law constant correction based on measurable properties of the organic and surfactant. N ote that E q. 3 differs slightly from the equation reported by $\mathrm{A} n-$ derson (1992), in that Eq. 3 accounts for the surfactant CM C, and is written in terms of the WSR, which is readily measurable. Although Eq. 3 can be rewritten in molar units, it is presented here in mass units to facilitate application to commercial surfactants, which may contain multiple components, and for which the molecular weights may be unknown. The work reported here does not attempt to directly test the validity of Eq. 3, but rather examines the applicability of Eq. 3 to air-stripper design. A $n$ important hypothesis of this work is that if the Henry's Law constant is corrected for solubilization through the use of Eq. 3, then Eqs. 1 and 2 can be used to quantitatively design air stripping systems.

The importance of accounting for the effect of surfactant solubilization on H enry's L aw constants cannot be overstated. Figure 1 shows the predicted effect of solubilization on the Henry's Law constant of tetrachloroethylene (PCE) in a TWEEN 80 nonionic surfactant solution. Note from the figure that the potential exists for a reduction of several orders of magnitude in the Henry's L aw constant at application-relevant surfactant concentrations. Neglecting this effect in the design of an air stripper could lead to a design that is unable to meet desired contaminant removal requirements.

Foam Formation. Surfactant adsorption to liquid interfaces can produce and stabilize foam (A damson and G ast, 1997). In tray air strippers, where air/water interfacial area is created by direct contact between air and water, the potential for foaming is very high. If the foam formed in an air stripper is stable and carries a significant quantity of water with it, it can create a situation where treated water is carried upward with the airflow to previous trays in the water flow path, diluting the contents of the trays and reducing the efficiency of the system. This process is known as entrainment (Berg, 1988). In extreme cases, entrainment flooding

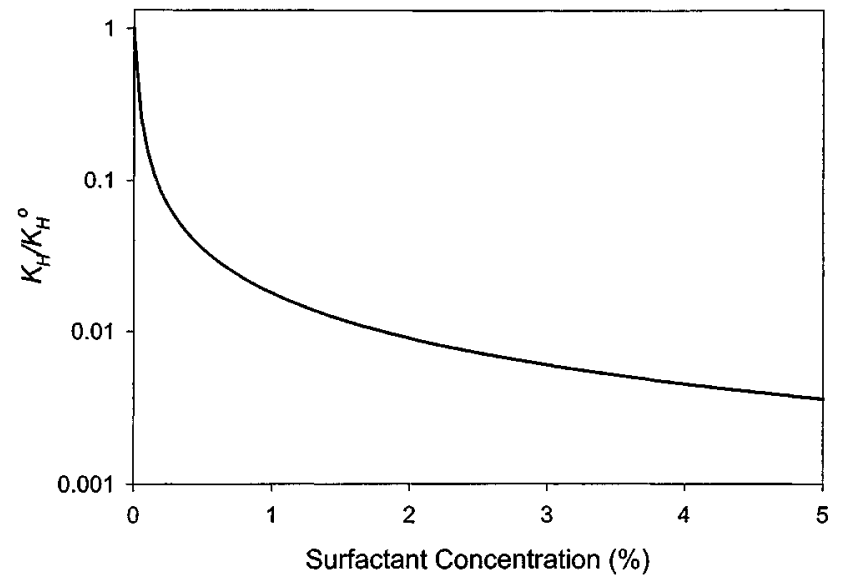

Figure 1. Effect of solubilization on the Henry's Law constant of PCE in surfactant (TWEEN 80) solutions, calculated with Eq. 3.

(the accumulation of water in the system due to entrainment) can occur. Increasing tray spacing and reducing air flow rates can reduce entrainment, although antifoaming agents will likely also be needed for most surfactant solutions.

In cases where entrainment can be minimized, foams can potentially have positive impacts on the performance of unsupported-area equipment by providing additional surface area for transfer between the water and air phases. For this effect to be significant, the foam formed must contain a reasonable quantity of water, and the water must be continuous with the bulk water in the trays (Berg, 1988). In the work reported here, no noticeable trends in air stripper performance were observed as a function of the quantity of foam present.

\section{Materials and Methods Air-stripping system}

A n EZ-Tray 4.2M S air stripper was purchased from QED Environmental (Ann Arbor, MI). The EZ-Tray 4.2M S is a two-tray commercial air stripper. Flow through each tray occurs in a reverse-flow arrangement, with water flowing around a central baffle on each tray. The active area of each tray is $0.262 \mathrm{~m}^{2}(47.6 \mathrm{~cm} \times 55.0 \mathrm{~cm})$, the vertical spacing between trays is $25.4 \mathrm{~cm}$, and the weir height is $5.1 \mathrm{~cm}$. Tray perforations are $4.75 \mathrm{~mm}$ in diameter, and arranged in 34 rows and 17 staggered columns on each tray ( 578 holes per tray). The E Z-Tray 4.2M S is rated for air flow rates up to approx. 6,000 $\mathrm{L} / \mathrm{min}\left(210 \mathrm{ft}^{3} / \mathrm{min}\right)$ and water flow rates up to approx. 95 $\mathrm{L} / \mathrm{min}$ (25 gal/min). For some experiments, air flow rates greater than $8,000 \mathrm{~L} / \mathrm{min}$ were used without discernable deviation from predicted air-stripper performance (although at extreme air flow rates, foaming became more difficult to control). Due to flow-rate limitations of the pump, water flow rates up to approx. $40 \mathrm{~L} / \mathrm{min}$ (10 gal/min) were used.

Air was supplied by a $5 \mathrm{hp} \mathrm{New} \mathrm{York} \mathrm{Blower} \mathrm{(Wil-}$ lowbrook, IL) 2004 blower, and an I waki Walchem (Holliston, M A ) M D-70RZT pump. The M D-70R ZT pump was selected because of its ability to operate over a wide range of 
flow rates, ranging from below $4 \mathrm{~L}$ /min to approx. $40 \mathrm{~L} / \mathrm{min}$, allowing large gas-to-liquid flow rate ratios to be explored. Liquid flow rates were controlled with a manual ball valve, and were quantified using a BadgerM eter (M ilwaukee, WI) model M 25 nutating disc flowmeter. A ir flow rates were controlled by a valve on the blower and a supplemental blast gate, and were measured using a D wyer (M ichigan City, IN) model 160-8 Pitot tube.

All connections to the EZ-Tray air stripper were made using PVC tubing. Drainage from the unit was controlled by gravity and a supplemental ball valve for back-pressure adjustment. The valve allowed the air flow rate to be varied while maintaining the level of the water in the sump of the EZ-Tray. Two 830-L (220-gal) tanks were used. A $3 \mathrm{~m} \times 0.3$ $\mathrm{m}$ packed-tower air stripper was also constructed and connected to the pump, blower, and tanks. The tower air stripper was packed with 1-in. Norton (A kron, OH) plastic Super Intalox Saddles. A system of valves allowed either air stripper to be operated, and to draw from either tank and drain into either tank. This system allowed the performance of the air strippers to be compared, and also allowed for recirculating operation, if desired. Sample ports were installed before and after each tray in the EZ-Tray air stripper, in addition to in the drain and the waterline after the pump. Experiments involved running the pump initially to fill the sump of the $E Z$ Tray air stripper (to prevent air from escaping through the water drain), adding antifoam to the inlet surfactant tank, and then turning on the blower and allowing the system to stabilize at the desired air and liquid flow rates for 5 to 10 min. All sample ports were then rapidly sampled into 4-mL vials with Teflon-lined caps. Sample vials were completely filled to minimize the potential for volatilization losses to headspace. (Note, however, that because surfactant reduces H enry's law constants dramatically, risks of volatilization were minimal.) Temperature was not controlled, but was monitored. Typical temperatures were slightly below $25 \mathrm{deg}$, and did not vary significantly, so temperature corrections were not applied in calculations. Procedures and information required for temperature correction are discussed in detail in the "R esults and Discussion" section.

\section{Materials}

The surfactant selected for this work was TWEEN $80(\mathrm{ICI}$ A mericas, Wilmington, DE), a POE 20 sorbitan monooleate nonionic surfactant. POE 20 sorbitan monooleate nonionic surfactants are widely used, and are produced under a number of different trade names (such as TWEEN 80, TM AZ 80, Witconol 2722, SORBAX PM 0-20). This surfactant has an average molecular weight of $1310 \mathrm{~g} / \mathrm{mol}$, an $\mathrm{HLB}$ of 15 , and has been reported to have a CM C of $13 \mathrm{mg} / \mathrm{L}$ (Becher, 1967). TWEEN 80 was selected because of its high solubilization capacity for chlorinated environmental contaminants, which makes it a good candidate for environmental applications. Concentrations of TWEEN 80 used ranged from approximately $0.7 \%$ to $3 \%$ by weight. Surfactant solutions were prepared by adding liquid TWEEN 80 to approx. 400-800 L of water and mixing vigorously for several hours, both by hand and with the MD-70RZT pump set to recirculate water from the tank.
Table 1. Properties of O rganic-Compounds Studied

\begin{tabular}{cccc}
\hline Compund & $\mathrm{K}_{\mathrm{H}}^{0}$ (dimensionless)* $^{*}$ & $\mathrm{WSR}^{\ddagger \ddagger}$ & Solubility $(\mathrm{mg} / \mathrm{L})^{* *}$ \\
\hline $\mathrm{PCE}$ & 0.724 & $0.818^{\dagger}$ & 149.0 \\
$\mathrm{TCE}$ & 0.403 & $1.49^{\dagger \dagger}$ & 1099.8 \\
$\mathrm{CB}$ & 0.154 & $0.880^{\ddagger}$ & 307.4 \\
Octane & 131.3 & $0.252^{\dagger \dagger}$ & 0.7165 \\
o-xylene & 0.212 & $0.512^{\dagger \dagger}$ & 191.5 \\
\hline
\end{tabular}

*H oward and M eylan 1997;

**D emond and Lindner, 1993;

${ }^{\dagger} M$ easured as a part of this work

${ }^{\mathrm{t}} \mathrm{Z}$ immerman and $\mathrm{H}$ ayes, 1999;

${ }^{\ddagger}$ Cowell and $\mathrm{H}$ ayes, 1999.

${ }^{\ddagger}$ W SR values correspond to solubilization of organic-compound in $\mathrm{POE}$ 20 sorbitan monooleate nonionic surfactant solution (TWEE N 80). All properties reported at $25^{\circ} \mathrm{C}$.

The antifoaming agent selected for this work was Trans-10 (Trans-Chemco, Bristol, WI), a 10\% silicone emulsion antifoam. Trans-10 is a food-grade antifoam, allowable in food to concentrations of $100 \mathrm{mg} / \mathrm{L}$. Typical concentrations used for air stripping ranged from 40 to $100 \mathrm{mg} / \mathrm{L}$ of Trans- 10 (equivalent to 4 to $10 \mathrm{mg} / \mathrm{L}$ of the pure antifoam material). The antifoam was dispersed in $500 \mathrm{~mL}$ of water prior to addition to surfactant solutions, to accelerate mixing. More details on antifoam performance are provided in the "R esults and Discussion" section.

O rganic compounds studied included tetrachloroethylene (PCE), trichloroethylene (TCE), chlorobenzene (CB), octane, and 0 -xylene. The compounds represent several classes of common volatile organic environmental contaminants (chlorinated alkenes, chlorinated aromatics, alkanes, aromatics). Properties of these compounds are provided in Table 1. Organic compounds were initially dissolved in high concentration TWEEN 80 solutions when possible (in some cases, emulsions were used, due to solubility limitations), and then added to the surfactant solution and mixed thoroughly overnight prior to beginning experiments.

\section{Analyses}

O rganic compound concentrations were analyzed using a H ewlett-Packard (Palo A Ito, CA) 5890 Gas Chromatograph with a flame ionization detector (FID) and an electron capture detector (ECD). The FID was used for higher concentration analyses, and for analysis of nonchlorinated organic compounds. The ECD was used for analysis of chlorinated compounds at lower concentrations. The method used for organic compound analysis has been described elsewhere (Zimmerman et al., 1999). D ue to low sensitivity of the ECD for chlorobenzene, chlorobenzene concentrations were analyzed using a V arian (W alnut Creek, CA) Star 3400CX G as Chromatograph connected to a Varian Saturn 2000 I on Trap $M$ ass Spectrometer. Samples from the air stripper were diluted with methanol prior to analysis, and were analyzed immediately after each air stripper run. Surfactant concentrations were determined using a Hewlett-Packard $1050 \mathrm{HPLC}$ and a Sedere (Richard Scientific, Novato, CA) SEDEX 55 evaporative light-scattering detector, using a previously developed method (Kibbey and $\mathrm{H}$ ayes, 1997; Zimmerman et al., 1999). WSR values presented in Table 1 were determined 
using an approach described by Zimmerman et al. (1999). The approach accounts for distribution of surfactant between the aqueous and nonaqueous phases during the measurement, providing a more accurate assessment of the WSR for systems involving polar organic compounds. N ote that WSR values are specific to each surfactant/organic compound combination, so the values in Table 1 should only be used for solutions of POE 20 sorbitan monooleate nonionic surfactants, such as TWEEN 80. For other surfactant/organic combinations, W SR s can be experimentally determined using the procedure described by Zimmerman et al. (1999).

\section{Results and Discussion}

\section{Air-stripper performance and design equation application}

Table 2 shows the operating conditions and results of all experiments conducted. Because the work described here was initially designed to provide specific air-stripper design information for a TWEEN 80-based surfactant field test at a
PCE -contaminated site in O scoda, MI, the largest number of experiments conducted involved PCE. However, experiments to evaluate air-stripper performance with other compounds were also conducted to determine the extent to which the PCE results are applicable to other systems. Note that some of the experiments shown in Table 2 (experiment numbers 13 and greater in Table 2) involved simultaneous air stripping of multiple components. In general, air-stripping performance for each component would be expected to be independent. In the experiments conducted for this work, no dependence on dissolved organic-compound composition was noted in airstripping results.

The approach used to interpret air-stripping data involved applying Eq. 3 to calculate the surfactant solubilization-corrected Henry's law constants $\left(K_{H}\right)$ (also shown in Table 2), and then using the corrected $\mathrm{K}_{H}$ values with $\mathrm{Eqs}$. 1 and 2 to model air-stripper performance. The overall tray efficiency, $\epsilon$ (Eq. 2), was determined by regression from the twenty PCE experimental results. A value of $\epsilon=0.601$ was found to work

Table 2. Tray Air Stripper Experimental Conditions and Results

\begin{tabular}{|c|c|c|c|c|c|c|c|c|c|c|c|}
\hline Comp. & $\begin{array}{l}\text { Exp. } \\
\text { No. }\end{array}$ & $\begin{array}{c}\text { Surfact. } \\
\text { Conc. (\%) }\end{array}$ & $\mathrm{K}_{\mathrm{H}}^{\circ}$ & $\begin{array}{c}\mathrm{K}_{\mathrm{H}} \\
\text { (Correct.) }\end{array}$ & $\begin{array}{l}\text { A ir Flow } \\
G(L / m i n)\end{array}$ & $\begin{array}{l}\text { W ater F low } \\
\mathrm{L} /(\mathrm{L} / \mathrm{min})\end{array}$ & $S\left(G K_{H} / L\right)$ & $\begin{array}{l}\text { Inlet Conc. } \\
(\mathrm{mg} / \mathrm{L})\end{array}$ & $\begin{array}{l}\text { M eas. O utlet } \\
\text { Conc. }(\mathrm{mg} / \mathrm{L})\end{array}$ & $\begin{array}{l}\text { Model Outlet } \\
\text { Conc. (mg/L) }\end{array}$ & $\begin{array}{c}\text { M odel O utlet } \\
\text { Conc. }(\mathrm{mg} / \mathrm{L}) \\
\text { without } \mathrm{K}_{\mathrm{H}} \\
\text { Correction }\end{array}$ \\
\hline PCE & 1 & 0.725 & 0.724 & $1.77 \times 10^{-2}$ & 4,894 & 19.3 & 4.49 & 229.316 & 32.817 & 30.363 & 0.432 \\
\hline PCE & 2 & 0.725 & 0.724 & $1.77 \times 10^{-2}$ & 4,894 & 19.3 & 4.49 & 192.801 & 22.981 & 25.529 & 0.363 \\
\hline PCE & 3 & 0.725 & 0.724 & $1.77 \times 10^{-2}$ & 4,894 & 19.3 & 4.49 & 163.356 & 22.376 & 21.630 & 0.308 \\
\hline PCE & 4 & 0.725 & 0.724 & $1.77 \times 10^{-2}$ & 4,894 & 19.5 & 4.45 & 86.898 & 10.781 & 11.619 & 0.166 \\
\hline PCE & 5 & 0.725 & 0.724 & $1.77 \times 10^{-2}$ & 4,894 & 19.5 & 4.45 & 69.410 & 7.001 & 9.281 & 0.132 \\
\hline PCE & 6 & 0.725 & 0.724 & $1.77 \times 10^{-2}$ & 8,341 & 39.8 & 3.72 & 35.208 & 6.371 & 5.612 & 0.083 \\
\hline PCE & 7 & 0.725 & 0.724 & $1.77 \times 10^{-2}$ & 8,341 & 39.8 & 3.72 & 32.209 & 5.426 & 5.134 & 0.076 \\
\hline PCE & 8 & 0.725 & 0.724 & $1.77 \times 10^{-2}$ & 5,783 & 40.9 & 2.51 & 1.092 & 0.293 & 0.250 & $4.1 \times 10^{-3}$ \\
\hline PCE & 9 & 0.725 & 0.724 & $1.77 \times 10^{-2}$ & 7,407 & 40.9 & 3.21 & 0.756 & 0.163 & 0.139 & $2.1 \times 10^{-3}$ \\
\hline PCE & 10 & 0.725 & 0.724 & $1.77 \times 10^{-2}$ & 6,451 & 25.0 & 4.58 & 0.576 & 0.089 & 0.075 & $1.1 \times 10^{-3}$ \\
\hline PCE & 11 & 0.725 & 0.724 & $1.77 \times 10^{-2}$ & 6,339 & 40.1 & 2.80 & 0.106 & 0.023 & 0.022 & $3.5 \times 10^{-4}$ \\
\hline PCE & 12 & 0.725 & 0.724 & $1.77 \times 10^{-2}$ & 6,339 & 40.1 & 2.80 & 0.050 & 0.011 & 0.010 & $1.7 \times 10^{-4}$ \\
\hline PCE & 13 & 3.043 & 0.724 & $4.31 \times 10^{-3}$ & 5,894 & 13.7 & 1.85 & 1.289 & 0.253 & 0.381 & $1.3 \times 10^{-3}$ \\
\hline PCE & 14 & 3.043 & 0.724 & $4.31 \times 10^{-3}$ & 5,894 & 37.1 & 0.68 & 1.149 & 0.472 & 0.640 & $3.8 \times 10^{-3}$ \\
\hline PCE & 15 & 3.043 & 0.724 & $4.31 \times 10^{-3}$ & 8,897 & 16.0 & 2.40 & 0.250 & 0.039 & 0.060 & $1.8 \times 10^{-4}$ \\
\hline PCE & 16 & 3.043 & 0.724 & $4.31 \times 10^{-3}$ & 6,895 & 15.6 & 1.90 & 0.221 & 0.036 & 0.064 & $2.1 \times 10^{-4}$ \\
\hline PCE & 17 & 3.043 & 0.724 & $4.31 \times 10^{-3}$ & 6,895 & 7.5 & 3.97 & 0.181 & 0.012 & 0.027 & $7.3 \times 10^{-5}$ \\
\hline PCE & 18 & 3.043 & 0.724 & $4.31 \times 10^{-3}$ & 6,895 & 7.5 & 3.97 & 0.166 & 0.010 & 0.025 & $6.6 \times 10^{-5}$ \\
\hline PCE & 19 & 1.598 & 0.724 & $8.16 \times 10^{-3}$ & 6,228 & 28.7 & 1.77 & 0.294 & 0.082 & 0.090 & $6.7 \times 10^{-4}$ \\
\hline PCE & 20 & 1.598 & 0.724 & $8.16 \times 10^{-3}$ & 6,228 & 28.7 & 1.77 & 0.245 & 0.078 & 0.075 & $5.6 \times 10^{-4}$ \\
\hline TCE & 13 & 3.043 & 0.403 & $9.54 \times 10^{-3}$ & 5,894 & 13.7 & 4.10 & 0.342 & 0.038 & 0.050 & $6.9 \times 10^{-4}$ \\
\hline TCE & 14 & 3.043 & 0.403 & $9.54 \times 10^{-3}$ & 5,894 & 37.1 & 1.52 & 0.291 & 0.072 & 0.100 & $1.9 \times 10^{-3}$ \\
\hline TCE & 15 & 3.043 & 0.403 & $9.54 \times 10^{-3}$ & 8,897 & 16.0 & 5.31 & 0.029 & $7.1 \times 10^{-3}$ & $3.3 \times 10^{-3}$ & $4.4 \times 10^{-5}$ \\
\hline TCE & 16 & 3.043 & 0.403 & $9.54 \times 10^{-3}$ & 6,895 & 15.6 & 4.21 & 0.026 & $4.4 \times 10^{-3}$ & $3.7 \times 10^{-3}$ & $5.1 \times 10^{-5}$ \\
\hline TCE & 17 & 3.043 & 0.403 & $9.54 \times 10^{-3}$ & 6,895 & 7.5 & 8.79 & 0.020 & $4.0 \times 10^{-3}$ & $1.3 \times 10^{-3}$ & $1.6 \times 10^{-5}$ \\
\hline TCE & 18 & 3.043 & 0.403 & $9.54 \times 10^{-3}$ & 6,895 & 7.5 & 8.79 & 0.017 & $3.7 \times 10^{-3}$ & $1.1 \times 10^{-3}$ & $1.4 \times 10^{-5}$ \\
\hline CB & 13 & 3.043 & 0.154 & $1.75 \times 10^{-3}$ & 5,894 & 13.7 & 0.75 & 0.223 & 0.061 & 0.119 & $1.4 \times 10^{-3}$ \\
\hline$C B$ & 14 & 3.043 & 0.154 & $1.75 \times 10^{-3}$ & 5,894 & 37.1 & 0.28 & 0.222 & 0.115 & 0.171 & $4.6 \times 10^{-3}$ \\
\hline$C B$ & 15 & 3.043 & 0.154 & $1.75 \times 10^{-3}$ & 8,897 & 16.0 & 0.97 & 0.052 & 0.014 & 0.024 & $2.4 \times 10^{-4}$ \\
\hline CB & 16 & 3.043 & 0.154 & $1.75 \times 10^{-3}$ & 6,895 & 15.6 & 0.77 & 0.050 & 0.012 & 0.026 & $3.1 \times 10^{-4}$ \\
\hline \multirow{3}{*}{\multicolumn{2}{|c|}{$\begin{array}{l}\text { n-O ctane } 21 \\
\text { n-O ctane } 22 \\
\text { n-O ctane } 23\end{array}$}} & 3.043 & 131.3 & $1.23 \times 10^{-2}$ & 6,117 & 39.4 & 1.91 & 14.470 & 6.864 & 4.174 & $9.5 \times 10^{-5}$ \\
\hline & & 3.043 & 131.3 & $1.23 \times 10^{-2}$ & 6,117 & 19.0 & 3.96 & 9.012 & 3.036 & 1.353 & $2.5 \times 10^{-5}$ \\
\hline & & 3.043 & 131.3 & $1.23 \times 10^{-2}$ & 6,117 & 19.0 & 3.95 & 5.503 & 1.949 & 0.828 & $1.5 \times 10^{-5}$ \\
\hline \multicolumn{2}{|c|}{ o-X ylene 19} & 1.598 & 0.212 & $4.84 \times 10^{-3}$ & 6,228 & 28.7 & 1.05 & 0.294 & 0.092 & 0.130 & 0.0029 \\
\hline \multicolumn{2}{|c|}{$0-X$ ylene 20} & 1.598 & 0.212 & $4.84 \times 10^{-3}$ & 6,228 & 28.7 & 1.05 & 0.245 & 0.062 & 0.108 & 0.0024 \\
\hline \multicolumn{2}{|c|}{ o-X ylene 21} & 3.043 & 0.212 & $2.57 \times 10^{-3}$ & 6,117 & 39.4 & 0.40 & 14.470 & 7.091 & 10.018 & 0.2102 \\
\hline \multicolumn{2}{|c|}{ o-X ylene 22} & 3.043 & 0.212 & $2.57 \times 10^{-3}$ & 6,117 & 19.0 & 0.83 & 9.012 & 2.010 & 4.555 & 0.0552 \\
\hline \multicolumn{2}{|c|}{$0-X$ ylene 23} & 3.043 & 0.212 & $2.57 \times 10^{-3}$ & 6,117 & 19.0 & 0.83 & 5.503 & 1.324 & 2.785 & 0.0338 \\
\hline
\end{tabular}




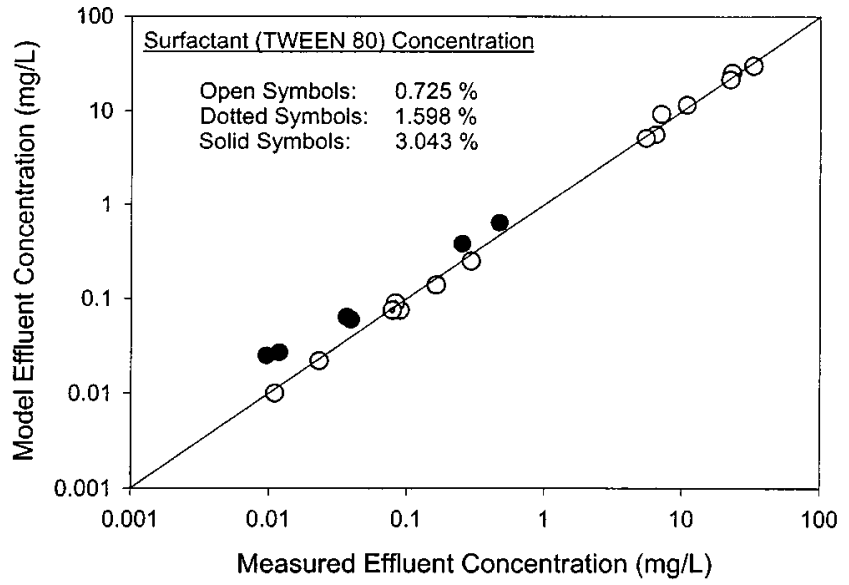

Figure 2. Measured vs. model-predicted PCE effluent concentrations.

The results in this figure were used to determine the value of overall tray efficiency $(\epsilon)$ used for all other compounds.

well for all PCE data with this air-stripping system, allowing the model to accurately describe air-stripper performance. This efficiency value was used directly for modeling all other compounds, as will be described below. Note that $\epsilon$ values may vary significantly from air stripper to air stripper, as a result of stagnant regions within trays and varying phase contact times resulting from differing tray geometries, so the $\epsilon$ should be determined experimentally for the air-stripper of interest. It is important to emphasize that the only adjustable parameter in the model is the overall tray efficiency $(\epsilon)$. All other parameters needed (organic compound solubility, $\mathrm{K}_{\mathrm{H}}^{0}$ WSR , CM C) are directly-measurable physical properties, and all, with the exception of the WSR (and sometimes the CM C), can usually be located in the literature.

Figure 2 shows the model vs. measured effluent concentrations for PCE. A s described earlier, the data in Figure 2 were used to determine $\epsilon$. Note that although these data cover three orders of magnitude in PCE concentration, twelve different gas/liquid flow-rate combinations, and three different surfactant concentrations, a single value of $\epsilon(0.601)$ works very well for all of these cases.

Figure 3 shows the model applied to all five compounds examined. The model predictions in Figure 3 are all based on the value of $\epsilon(0.601)$ determined from the PCE experiments. In general, model predictions are very good in all cases, supporting the hypothesis that overall tray efficiency $(\epsilon)$ is only weakly influenced by compound properties. Based on this result, it seems reasonable to use a single value of $\epsilon$ for preliminary design of tray air strippers for removal of contaminants from surfactant solutions.

Figure 4 shows a comparison between model predictions in Figure 3 and model predictions using uncorrected $\mathrm{K}_{\mathrm{H}}^{0}$ values. (R esults of all experiments are also presented in Table 2). Note that neglecting to correct $\mathrm{K}_{\mathrm{H}}^{0}$ for surfactant solubilization can produce a several-orders-of-magnitude overprediction of air-stripper performance, and the extent of the error will vary dramatically from compound to compound. For example, from Figure 4, it is apparent that neglecting surfactant solubilization for octane would lead to actual octane

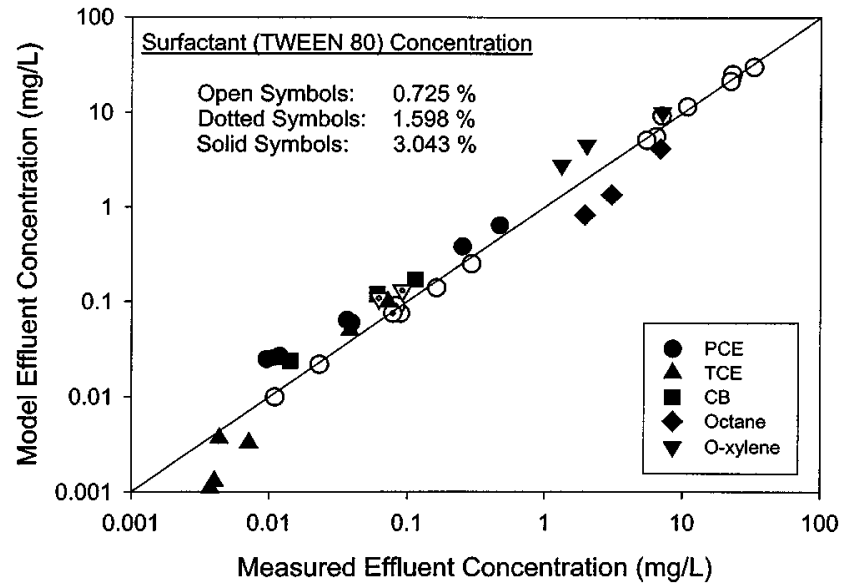

Figure 3. Measured vs. model-predicted effluent concentrations for all compounds studied.

concentrations in air-stripper effluent five orders of magnitude greater than predicted concentrations-clearly an undesirable situation. Note that the potential magnitude of this error is significantly greater than any error that might be introduced by using an incorrect value of tray efficiency.

Although model predictions (as shown in Figures 2 and 3, and Table 2) are good enough for most design situations, some discrepancies between measured and model-predicted effluent concentrations are observed. Two potential reasons for the discrepancies are (1) Values in the literature for compound physical properties, such as solubility and $\mathrm{K}_{\mathrm{H}}^{0}$, can vary significantly. A lthough we have used the same sources for all values of solubility (D emond and Lindner, 1993) and $\mathrm{K}_{\mathrm{H}}^{0}$ (Howard and Meylan, 1997), these two sources are themselves compilations of data from different sources. $V$ ariability in literature values may account for some of the differences between measured and model-predicted air-stripper results from compound to compound. (2) As discussed in the "Background" section, the use of WSR to correct for

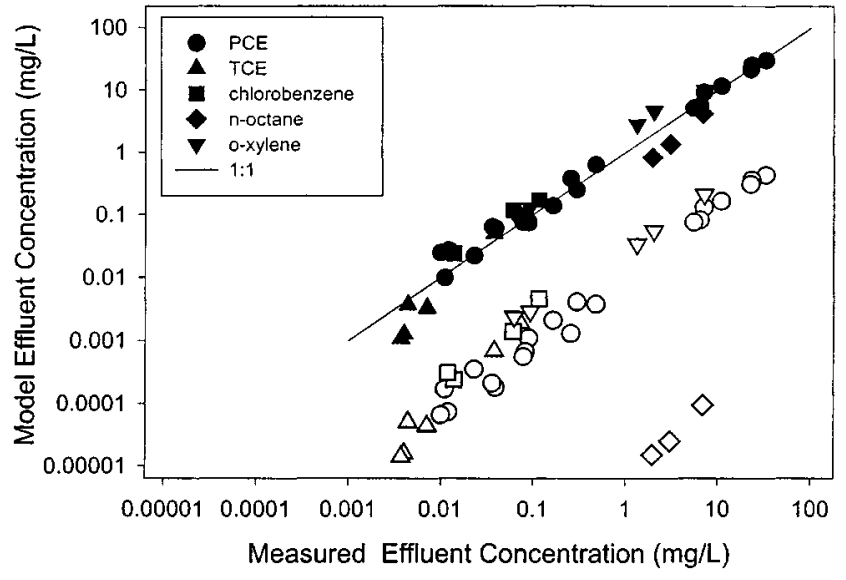

Figure 4. Effect of neglecting Henry's law constant solubilization correction on model prediction. Open symbols correspond to uncorrected (literature) $\mathrm{K}_{\mathrm{H}}^{0}$ values from Table 1. 
solubilization-based volatility reduction implicitly assumes that the partitioning behavior of organic compounds between water and micelles does not change over the entire organiccompound concentration range. This assumption may not be equally valid for all compounds, so deviation from this assumption may be responsible for the model under- or overpredicting the air-stripper performance for some compounds relative to others. Nevertheless, even with these potential difficulties, it is apparent from Figure 4 that the predictions of the model with correction for $\mathrm{K}_{\mathrm{H}}$ are far superior to predictions made with uncorrected $\mathrm{K}_{\mathrm{H}}^{0}$, and should be more than adequate for most air-stripper design situations involving surfactant solutions.

O ne question that might be asked is: Why not just measure $\mathrm{K}_{\mathrm{H}}$ values for organic compounds in the surfactant solution of interest? A lthough this approach would work, the fact that $\mathrm{K}_{\mathrm{H}}$ values are very low in surfactant solutions makes their determination potentially analytically difficult. In addition, $\mathrm{K}_{\mathrm{H}}$ values would need to be determined at every surfactant concentration likely to be encountered. Equation 3, on the other hand, allows calculation of corrected $\mathrm{K}_{\mathrm{H}}$ values as a function of surfactant concentration, a fact that may be very useful for applications where the expected surfactant concentration may vary.

\section{Foam control}

The antifoaming agent selected for this work was Trans-10, a food-grade $10 \%$ silicone polymer emulsion. With the exception of very-high-air-flow conditions ( $>8,000 \mathrm{~L} / \mathrm{min}$ air, far above the rated capacity of the air stripper), Trans-10 was found to sufficiently control foaming in the air-stripper under all conditions tested. Typical antifoam concentrations used ranged from 40 to $100 \mathrm{mg} / \mathrm{L}$. For solutions that were run through the air-stripper multiple times, new antifoam typically had to be added prior to each run. It appeared that this resulted from loss of antifoam to the inside walls of the air stripper, as well as clumping of the antifoam that occurred after it was run through the air-stripper. B ecause of the low concentrations used and the low cost of the antifoam, loss of antifoaming agent effectiveness with use provided only a minor inconvenience.

$V$ arying the quantity of antifoam added to surfactant solutions varied the amount of foaming in the air-stripper, and very high concentrations of antifoam ( $>100 \mathrm{mg} / \mathrm{L}$ ) were able to eliminate foaming altogether. The quantity of foam present did not appear to have any impact on the air-stripper compound removal performance for the compounds examined here.

A Ithough a silicone antifoam like Trans-10 would likely be a good choice for some applications because of its low toxicity and low cost, silicone polymer emulsion antifoaming agents like Trans-10 may cause problems with ultrafiltration systems that may be used after air stripping for some applications. A s such, future work should be directed at systematically examining and identifying other antifoaming agents for surfactant-based air-stripping applications.

Because different surfactants foam to different extents, effectiveness of antifoaming agents should be evaluated with the surfactant of interest, preferably in a full-scale tray airstripping unit. In separate foaming tests, QED Environmen- tal Systems and Carbonair Environmental Systems (New $\mathrm{H}$ ope, $\mathrm{MN}$ ) tested different anionic surfactants for foaming in their respective air strippers. QED tested high concentrations of A erosol M A (C ytec Industries, W est Paterson, $\mathrm{NJ}$ ) in a 6-tray air-stripper, and found that antifoam levels comparable to those used in this study were sufficient to control foaming. Carbonair tested high concentrations of $D$ awn dishwashing liquid (Procter and $\mathrm{Gamble}$, Cincinnati, $\mathrm{OH}$ ) in a 2-tray air stripper, and found that the system required an order of magnitude more antifoam than was used in this study, likely as a result of foam-enhancing surfactants added to dishwashing liquids.

\section{Temperature correction}

As described in the "Background" section, the results presented here were determined at temperatures near $25^{\circ} \mathrm{C}$, and are based on reported literature values of solubility and $\mathrm{H}$ enry's law constant $\left(\mathrm{K}_{\mathrm{H}}^{0}\right)$. A ccounting for temperature variation in model calculations would require information on the temperature dependence of three values: organic-compound aqueous solubility, $\mathrm{K}_{\mathrm{H}}^{0}$, and WSR. Prediction of the temperature dependence of solubility and $\mathrm{K}_{\mathrm{H}}^{0}$ is straightforward, and procedures for making these calculations are described elsewhere (Kavanaugh and Trussell, 1980; Grant and Higuchi, 1990; Schwarzenbach, et al., 1993). In general, for most organic-compounds, both solubility and $\mathrm{K}_{\mathrm{H}}^{0}$ would be expected to increase with increasing temperature. Prediction of the temperature dependence of WSR is not straightforward, however, and would likely require that measurements of W SR be made as a function of temperature. In general, it would be expected that decreasing temperature would decrease W SR values (Attwood and Florence, 1983; Pennell et al., 1997). Because changes in the WSR and $\mathrm{K}_{\mathrm{H}}^{0}$ have opposite effects on the solubilization-corrected $K_{H}$ value, it is possible that air-stripper performance could potentially even increase with decreasing temperature for cases where W SR varies significantly with temperature.

\section{E ffect of $K_{H}$ on air stripping}

Because surfactants can dramatically reduce Henry's law constants $\left(\mathrm{K}_{\mathrm{H}}\right)$, standard air-stripping system configurations may not provide optimal performance. Figure 5 shows predicted air-stripper effluent concentration (from Eq. 1) as a function of the number of theoretical trays, shown for several different stripping factor (S) values. R ecall that $\mathrm{S}$ is proportional to $\mathrm{K}_{\mathrm{H}}$ for given gas and liquid flow rates. From Figure 5 , it is apparent that for values of $S<1$, concentration of a contaminant will not be reduced to zero, even with an infinite number of trays. It can be shown that if $S<1$, as the number of trays approaches infinity, the percent removal produced by the air-stripper approaches $S \times 100$. This fact has significance for surfactant systems, because of the low $\mathrm{K}_{\mathrm{H}}$ (and $S$ ) values they produce. (Note that many of the experiments in Table 2 have $S$ values near or below 1.) It is important to note that the behavior shown in Figure 5 is a result of the mass balance, and is qualitatively true for all types of countercurrent air-strippers. As a result, just as a tray air stripper with an infinite number of trays will not be able to completely remove a contaminant with $S<1$, an infinitely tall 


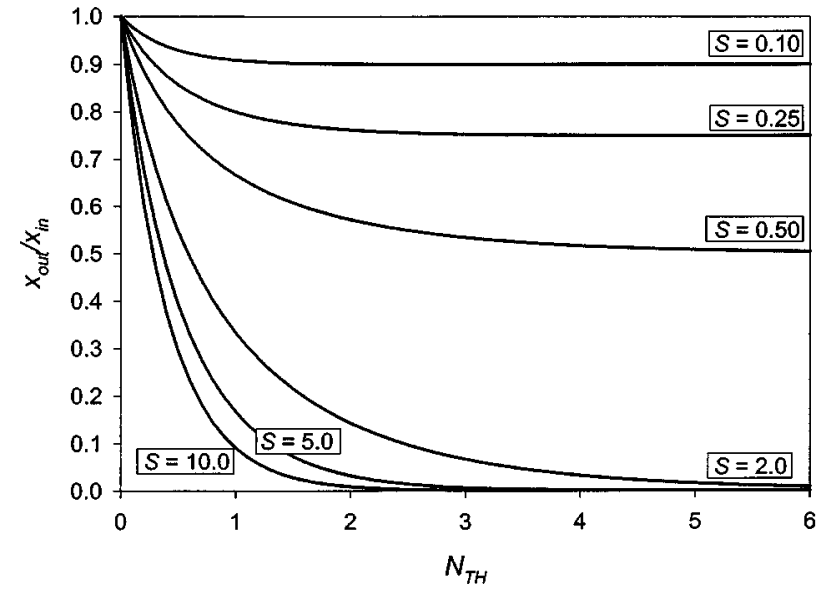

Figure 5. Influence of the stripping factor, $S$, on air-stripper performance.

packed-tower air-stripper (that is, one with an infinite number of mass-transfer units) will not be able to completely remove a contaminant with $\mathrm{S}<1$.

This result indicates that a good strategy for air stripper design for low-volatility systems would be to design for several small air strippers in series or parallel, rather than using a single large air stripper. This approach would work not only for surfactant systems, but also for removal of low-volatility compounds from water. R unning multiple air strippers in series takes advantage of the fact that even low-volatility components will be removed to some extent by a single air stripper if $S<1$. If the percent removal produced by a single air stripper, $\left[(1-f) \times 100\right.$, where $\left.f=x_{\text {out }} / x_{\text {in }}\right]$ is lower than desired, operating $n_{s}$ air strippers in series will produce an overall percent removal given by $\left(1-f^{n_{s}}\right) \times 100$. For nonvolatile compounds, multiple small air strippers in series may be able to produce the desired contaminant removal, while the same number of trays in a single air stripper will not.

R unning multiple air strippers in parallel can also increase removal by reducing the liquid flow rate through each air stripper, causing an increase in $\mathrm{S}$ for each air stripper. To determine whether series or parallel operation will require fewer air-strippers, E q. 4 can be evaluated. Equation 4 calculates the number of air strippers in series, $n_{s}$, that are needed to produce the same amount of compound removal as $n_{p}$ air strippers in parallel:

$$
\mathrm{n}_{\mathrm{s}}=\frac{\log \left[\left(1-\mathrm{n}_{\mathrm{p}} \mathrm{S}^{\prime}\right) /\left(1-\left(\mathrm{n}_{\mathrm{p}} \mathrm{S}^{\prime}\right)^{\left(\mathrm{N}_{T H}^{\prime}+1\right)}\right)\right]}{\log \left[\left(1-\mathrm{S}^{\prime}\right) /\left(1-\mathrm{S}^{\prime\left(\mathrm{N}_{T H}^{\prime}+1\right)}\right)\right]}
$$

where

$\mathrm{n}_{\mathrm{s}}=$ number of air strippers in series;

$\mathrm{n}_{\mathrm{p}}=$ number of air-strippers in parallel;

$\mathrm{S}^{\prime}=$ stripping factor calculated based on the total liquid flow to be treated, and the gas flow to each airstripper; and

$\mathrm{N}_{\mathrm{TH}^{\prime}}=$ number of theoretical trays in each air-stripper.

In general, Eq. 4 predicts that series operation will always require fewer air strippers than parallel operation when $S^{\prime}$ is greater than 1 . When $S^{\prime}$ is less than 1 , series operation will still typically require fewer air-strippers than parallel operation for low values of $\mathrm{N}_{\mathrm{TH}}^{\prime}$ (that is systems, with few trays), although in some cases low $\mathrm{S}^{\prime}$ values coupled with moderately large $\mathrm{N}_{\mathrm{T}}^{\prime}$ values will favor parallel operation.

\section{Comparison with packed tower performance}

A $3 \mathrm{~m} \times 0.3 \mathrm{~m}$ packed tower was operated for selected cases for comparison with the sieve-tray air-stripper. R esults of packed-tower performance are provided in Table 3. O verall, it is apparent that the packed tower tested was not able to achieve the same level of removal as would be predicted for the tray air stripper at the same gas and liquid flow rates (prediction based on the model described earlier). Only in the cases where $S$ was significantly below 1 and removal by the packed tower was near the maximum possible limited by equilibrium $[(1-f)$ is approaching $S$; for example, experiments 28 and 29 for chlorobenzene] is the packed-tower performance comparable to the tray-air stripper performance. The other cases indicate that a tower between 5 and 10 meters in height would be needed to match the removal of the 2-tray air-stripper, depending on the compound considered. This result highlights the size advantages of tray air strippers.

Table 3. Packed-Tower Air-Stripper Performance Comparison

\begin{tabular}{|c|c|c|c|c|c|c|c|c|c|c|}
\hline Comp. & $\begin{array}{l}\text { Exp. } \\
\text { No. }\end{array}$ & $\begin{array}{c}\text { Surfact. } \\
\text { Conc. (\%) }\end{array}$ & $\mathrm{K}_{\mathrm{H}}^{0}$ & $\begin{array}{c}\mathrm{K}_{\mathrm{H}} \\
\text { (Corrected) }\end{array}$ & $\begin{array}{l}\text { A ir Flow } \\
\text { G (L/min) }\end{array}$ & $\begin{array}{c}\text { W ater Flow } \\
\mathrm{L}(\mathrm{L} / \mathrm{min})\end{array}$ & $S\left(G K_{H} / L\right)$ & $\%$ R emoval & $\begin{array}{c}\text { Pred. \% } \\
\text { R emoval for Tray } \\
\text { Sys. at Same } \\
\text { S }\end{array}$ & $\begin{array}{c}\text { H eight of Packed } \\
\text { Tower to A chieve } \\
\text { Same R emoval } \\
\text { (m) }\end{array}$ \\
\hline PCE & 24 & 0.725 & 0.724 & $1.77 \times 10^{-2}$ & 4,671 & 5.3 & 15.63 & $76.83 \%$ & $96.56 \%$ & 7.1 \\
\hline PCE & 25 & 0.725 & 0.724 & $1.77 \times 10^{-2}$ & 4,449 & 4.3 & 18.44 & $67.63 \%$ & $97.15 \%$ & 9.8 \\
\hline PCE & 26 & 0.725 & 0.724 & $1.77 \times 10^{-2}$ & 4,449 & 4.3 & 18.44 & $68.80 \%$ & $97.15 \%$ & 9.5 \\
\hline PCE & 27 & 0.725 & 0.724 & $1.77 \times 10^{-2}$ & 6,006 & 11.2 & 9.47 & $62.39 \%$ & $93.97 \%$ & 9.1 \\
\hline PCE & 28 & 3.043 & 0.724 & $4.31 \times 10^{-3}$ & 5,227 & 23.1 & 0.97 & $32.83 \%$ & $53.91 \%$ & 7.4 \\
\hline PCE & 29 & 3.043 & 0.724 & $4.31 \times 10^{-3}$ & 3,003 & 23.0 & 0.56 & $27.41 \%$ & $39.14 \%$ & 6.1 \\
\hline PCE & 30 & 3.043 & 0.724 & $4.31 \times 10^{-3}$ & 3,003 & 6.6 & 1.97 & $51.34 \%$ & $71.92 \%$ & 5.9 \\
\hline TCE & 28 & 3.043 & 0.403 & $9.54 \times 10^{-3}$ & 5,227 & 23.1 & 2.16 & $49.25 \%$ & $73.95 \%$ & 6.7 \\
\hline TCE & 29 & 3.043 & 0.403 & $9.54 \times 10^{-3}$ & 3,003 & 23.0 & 1.25 & $47.08 \%$ & $60.56 \%$ & 5.0 \\
\hline $\mathrm{TCE}$ & 30 & 3.043 & 0.403 & $9.54 \times 10^{-3}$ & 3,003 & 6.6 & 4.37 & $67.58 \%$ & $86.37 \%$ & 5.6 \\
\hline$C B$ & 28 & 3.043 & 0.154 & $1.75 \times 10^{-3}$ & 5,227 & 23.1 & 0.40 & $32.59 \%$ & $30.58 \%$ & 2.5 \\
\hline$C B$ & 29 & 3.043 & 0.154 & $1.75 \times 10^{-3}$ & 3,003 & 23.0 & 0.23 & $21.86 \%$ & $19.76 \%$ & 1.9 \\
\hline$C B$ & 30 & 3.043 & 0.154 & $1.75 \times 10^{-3}$ & 3,003 & 6.6 & 0.80 & $33.93 \%$ & $48.52 \%$ & 6.0 \\
\hline
\end{tabular}


Because commercial 6-tray air strippers can be purchased with heights lower than the laboratory-scale packed-tower air stripper examined here, the small size of the tray air stripper may offset the need to add antifoaming agent for many applications. In addition, the ability to use higher gas-to-liquid flow-rate ratios with tray air strippers makes them ideal for removal of compounds with low volatility, such as those solubilized in surfactant solutions.

\section{Conclusions}

The results presented here demonstrate that (1) surfactant-containing solutions can be successfully treated with sieve-tray air-stripping systems, and (2) quantitative correction of Henry's law constants $\left(\mathrm{K}_{\mathrm{H}}^{0}\right)$ for surfactant solubilization-induced volatility reduction can lead to accurate predictions of air-stripper performance, allowing for quantitative design of tray air strippers for surfactant systems. This article discusses an approach that could be used for temperature correction of air-stripping predictions, and presents a strategy for design of air-stripping systems for low-volatility compounds. Future work addressed at determining the impact of temperature on solubilization (WSR) would provide useful information for predicting temperature dependence of airstripping performance with surfactant solutions.

\section{Acknowledgments}

Funding for the research was provided by the State of $M$ ichigan Department of Environmental Q uality. The content of this publication does not necessarily represent the views of this agency. The authors thank Tom Y avaraski for performing the GC/M S analysis of chlorobenzene, and for his assistance with the other chemical analyses involved in this work. In addition, the authors thank Julie Zimmerman and $M$ atthew Cowell for providing several of the WSR values used in model calculations and for their assistance in some of the initial air-stripper experiments.

\section{Notation}

$\mathrm{x}_{\text {out }}=$ aqueous concentration leaving the air stripper

$x_{\text {in }}=$ aqueous concentration entering the air stripper

$y_{\text {in }}=$ gas concentration entering the air stripper

$\mathrm{N}_{\mathrm{TH}}=$ number of theoretical trays in the air stripper

$\mathrm{N}_{\mathrm{AC}}=$ number of actual trays in the air stripper

$\mathrm{S}=$ stripping factor

$\mathrm{G}=$ gas flow rate

$\mathrm{L}=$ liquid flow rate

$\mathrm{K}_{\mathrm{H}}^{0}=\mathrm{H}$ enry's L aw constant in the absence of surfactant

$\mathrm{K}_{\mathrm{H}}=\mathrm{H}$ enry's L aw constant corrected for solubilization

$\mathrm{C}_{\text {surf }}=$ aqueous surfactant concentration in mass units

CMC $=$ critical micelle concentration of the surfactant in mass units

$\mathrm{S}_{\text {org }}=$ aqueous solubility of the organic compound in mass units

WSR $=$ weight solubilization ratio for the surfactant/organic compound

$\mathrm{C}_{\text {org }}=$ total organic compound concentration in mass units

$\mathrm{n}_{\mathrm{s}}=$ number of air strippers in series

$\mathrm{n}_{\mathrm{p}}=$ number of air strippers in parallel

$\mathrm{S}^{\prime}=$ stripping factor calculated based on the total liquid flow to be treated, and the gas flow to each air-stripper (for multiple stripper systems)

$\mathrm{N}_{\mathrm{TH}^{\prime}}=$ is the number of theoretical trays in each air stripper (for multiple stripper systems)

\section{G reek letter}

$\epsilon=$ overall tray efficiency

\section{Literature Cited}

A damson, A. W ., and A. P. G ast, Physical Chemistry of Surfaces, 6th ed., Wiley, New Y ork (1997).

A nderson, M. A. "Influence of Surfactants on Vapor-Liquid Partitioning," Environ. Sci. Technol., 26, 2186 (1992).

A ttwood, D., and A. T. Florence, Surfactant Systems, Their Chemistry, Pharmacy and Biology, Chapman \& Hall, N ew Y ork (1983).

Becher, P. "M icelle Formation in A queous and Nonaqueous Solutions," Nonionic Surfactants M. J. Schick, ed.; D ekker, N ew Y ork (1967).

Bennett, D. J., A. S. Kao, and L. W. Wong, "M echanistic A nalysis of Sieve Tray Froth Height and Entrainment," AIChE J., 41, 2067 (1995).

Berg, J . C., "The E ffect of Surface-A ctive A gents in Distillation Processes," Surfactants in Chemical Process E ngineering, Surfactant Science Series, Vol. 28, D. T. Wasan, M. E. Ginn, and D. O. Shah, eds., D ekker, N ew Y ork (1988).

Chen, G. X., and K. T. Chuang "Prediction of Point Efficiency for Sieve Trays in Distillation," Ind. and Eng. Chem. Res., 32, 701 (1993).

Chiang, P.-C., C.-H. H ung, J. C. M ar, and E. E. Chung, "Henry's Constants and $M$ ass Transfer Coefficients of $\mathrm{H}$ alogenated O rganic Pollutants in an Air Stripping Packed Column," Water Sci. and Technol., 38, 287 (1998).

Choori, U. N., J. F. Scamehorn, and J. H. O'H aver, "R emoval of Volatile Organic Compounds from Surfactant Solutions by Flash V acuum Stripping in a Packed Column," G round Water Monit. Remediation, 18, 157 (1998).

Clarke, A. N., K. H. O ma, M. M. M egehee, and D. J. Wilson, "Soil Clean-U p by Surfactant Washing: II. D esign and Evaluation of the Components of the Pilot-Scale Surfactant R ecycle System," Sep. Sci. Technol., 28, 2103 (1993).

Cowell, M. A., and K. F. H ayes, unpublished data (1999).

Demond, A. H, and A. S. Lindner, "Estimation of Interfacial Tension Between Organic Liquids and Water," Environ. Sci. Technol., 27, 2318 (1993).

D vorak, B. I., D. F. Lawler, J. R . F air, and N. E. H andler, "E valuation of the $O$ nda Correlations for M ass Transfer with Large R andom Packings," Environ. Sci. Technol., 30, 945 (1996).

Grant, D. J. W., and T. H iguchi, Solubility Behavior of Organic Compounds, Techniques of Chemistry, Vol. 21, W. H. Sanders, Series ed.; Wiley, N ew Y ork (1990).

H oward, P. H., and W. M. M eylan, eds., Handbook of Physical Properties of Organic Chemicals, CRC, Lewis Publishers, Boca R aton, FL (1997).

Kavanaugh, M . C., and R. R. Trussell, "D esign of A eration Towers to Strip Volatile Contaminants from D rinking Water," J. AWWA, 72, 684 (1980).

Kibbey, T. C. G., and K. F. H ayes, "A M ulti-Component A nalysis of the Sorption of Polydisperse E thoxylated Nonionic Surfactants to A quifer M aterials: Equilibrium Sorption Behavior," Environ. Sci. Technol., 31, 1171 (1997).

Lipe, K. M., D. A. Sabatini, M. A. Hasegawa, and J. H. Harwell, "M icellar-E nhanced U Itrafiltration and A ir Stripping for Surfactant Contaminant Separation and Surfactant R euse,"'G round Water M onit. Remediation, 16, 85 (1996).

O ma, K. H., A. N. Clarke, M. M. M egehee, and D. J. Wilson, "Soil Clean-U p by Surfactant Washing. III. Design and Evaluation of the Integrated Pilot-Scale Surfactant Recycle System," Sep. Sci. Technol., 28, 2319 (1993).

Pennell, K. D., A. M. A dinolfi, L. M. A briola, and M. S. Diallo, "Solubilization of D odecane, Tetrachloroethylene, and 1,2-Dichlorobenzene in M icellar Solutions of Ethoxylated N onionic Surfactants," Environ. Sci. and Tech., 31, 1382 (1997).

Perry, R. H., and D. W. Green, Perry's Chemical Engineer's Handbook, 7th ed., M cG raw-Hill, N ew Y ork (1997).

Prado, M., and J. Fair "Fundamental Model for the Prediction of Sieve Tray Efficiency," Ind. Eng. Chem. Res., 29, 1031 (1990). 
Schwarzenbach, R. P., P. M. Gschwend, and D. M. Imboden, Environmental Organic Chemistry, Wiley, N ew Y ork (1993).

Staudinger, J., W. R. Knocke, and C. W. R andall, "Evaluating the Onda M ass Transfer Correlation for the Design of Packed-Column A ir Stripping," J. Amer. Water Works Assoc., 82, 73 (1990).

Zimmerman, J. B., T. C. G. Kibbey, M. A. Cowell, and K. F. Hayes, "Partitioning of Ethoxylated Nonionic Surfactants into Non-
aqueous-Phase Organic Liquids: Influence on Solubilization Behavior," Environ. Sci. Technol., 33, 169 (1999).

Zimmerman, J., and K. F. H ayes, unpublished data (1999).

M anuscript received Dec. 28, 2000, and revision received Jan. 10, 2001. 